\title{
Cellular Symmetry Breaking during Caenorhabditis elegans Development
}

\author{
Edwin Munro ${ }^{1}$ and Bruce Bowerman ${ }^{2}$ \\ ${ }^{1}$ Center for Cell Dynamics, Friday Harbor Labs, 620 University Rd, Friday Harbor WA 98250 \\ ${ }^{2}$ Institute of Molecular Biology, University of Oregon, 1370 Franklin Boulevard, Eugene, Oregon 97403 \\ Correspondence: munroem@u.washington.edu
}

The nematode worm Caenorhabditis elegans has produced a wellspring of insights into mechanisms that govern cellular symmetry breaking during animal development. Here we focus on two highly conserved systems that underlie many of the key symmetry-breaking events that occur during embryonic and larval development in the worm. One involves the interplay between Par proteins, Rho GTPases, and the actomyosin cytoskeleton and mediates asymmetric cell divisions that establish the germline. The other uses elements of the Wnt signaling pathway and a highly reiterative mechanism that distinguishes anterior from posterior daughter cell fates. Much of what we know about these systems comes from intensive study of a few key events-Par/Rho/actomyosin-mediated polarization of the zygote in response to a sperm-derived cue and the Wnt-mediated induction of endoderm at the four-cell stage. However, a growing body of work is revealing how C. elegans exploits elements/variants of these systems to accomplish a diversity of symmetry-breaking tasks throughout embryonic and larval development.

$\mathrm{O}$ ver the past few decades, the $C$. elegans embryo has become a premiere system for studying cellular symmetry breaking in a developmental context. During C. elegans development, nearly every division produces daughter cells with different developmental trajectories. In some cases, these differences are imposed on daughters before or after division through inductive signals, but many of these divisions are intrinsically asymmetric - an initial symmetry-breaking step creates polarized distributions or activities of factors that control developmental potential. Registration of the cleavage plane with the axis of polarity then ensures differential inheritance of these potentials. With respect to cell fates, the output of these asymmetric divisions is amazingly diverse, yet the embryo seems to accomplish this diversity through variants of a few conserved symmetry-breaking systems. Thus the C. elegans embryo provides an exceptional opportunity to explore not only the core mechanisms underlying cellular symmetry breaking, but also how evolution can reconfigure these mechanisms to do different but related jobs in multiple contexts.

In this review, we focus most of our attention on two conserved systems that together

Editors: Rong Li and Bruce Bowerman

Additional Perspectives on Symmetry Breaking in Biology available at www.cshperspectives.org

Copyright (C) 2009 Cold Spring Harbor Laboratory Press; all rights reserved; doi: 10.1101/cshperspect.a003400

Cite this article as Cold Spring Harb Perspect Biol 2009;1:a003400 
account for much of the cellular asymmetry observed during C. elegans embryogenesis. The first, which is best known for its role in the early asymmetric cell divisions that segregate germline from the soma, involves a complex interplay between Par proteins, Rhofamily GTPases, and the actomyosin cytoskeleton. Interestingly, the embryo exploits elements of this same system to break symmetry during cleavage furrow specification and to establish apicobasal polarity in early embryonic cells and in the first true embryonic epithelia. The second system we focus on involves an unusual application of WNT signaling pathway components and is used reiteratively throughout embryonic and larval development to distinguish anterior and posterior daughter cell fates. Rather than comprehensively review these systems, we highlight topics not extensively covered in other reviews.

\section{SYMMETRY BREAKING IN P0}

The study of cellular symmetry breaking in the C. elegans zygote (called $\mathrm{P}_{0}$ ) dates back to the discoveries of germline $\mathrm{P}$ granule segregation and the partitioning-defective mutants (Strome and Wood 1983; Kemphues et al. 1988 ) in the 1980s. The P0 zygote polarizes in response to a transient cue associated with the centrosomes/microtubule organizing center (the sperm MTOC) that forms near the site of sperm entry about 25 min after fertilization, following meiosis (Goldstein and Hird 1996). Acting on an essentially unpolarized cell, the sperm cue triggers a rapid reorganization of the cell cortex, accompanied by the de novo enrichment of conserved polarity determinants known as Par proteins within complementary anterior and posterior cortical domains. The PDZ domain proteins Par-3 and Par-6 and the atypical protein kinase PKC-3 localize to the anterior cortex, whereas the serine/threonine kinase Par-1 and the ring domain protein Par-2 localize to the posterior. These cortical asymmetries are subsequently maintained as the female pronucleus migrates to meet the male pronucleus in the posterior of the zygote, and as they move together toward the zygote's center to form the first mitotic spindle. The asymmetrically localized Par proteins in turn shape the distributions of cytoplasmic factors that specify different developmental potentials. They also shape the distributions of cortical factors that position the mitotic spindle, and thus the first cleavage furrow, to segregate correctly developmental potentials to unequally sized daughters. These later events are causally downstream of the symmetry-breaking mechanism and have been extensively reviewed elsewhere (Cowan and Hyman 2004a; Munro 2006; Goldstein and Macara 2007; Galli and van den Heuvel 2008). Here we focus on the initial symmetry-breaking events that shape cortical polarity in response to the sperm cue. We focus on C. elegans but also cite regulatory interactions known from work in other organisms.

Asymmetric Contraction and Cortical Flows Segregate Cortical Factors to Establish Cell Polarity

The outline of a mechanism for symmetry breaking in $\mathrm{P}_{0}$ has emerged in the last few years (Figs. 1 and 2). Near the end of meiosis, the cortex is essentially unpolarized. The ultimately "anterior" Par proteins (Par-3, Par-6, and $\mathrm{Pkc}-3$ ) are distributed throughout the cortex, where they are required to prevent accumulation of Par-1 and Par-2, probably through phosphorylation of Par-1 and Par-2 by Pkc-3 (Benton and St Johnston 2003; Hao et al. 2006). Actomyosin contractility drives transient focal contractions throughout the cortex, which concentrate F-actin and myosin into foci with a characteristic spacing of $\sim 2-3$ $\mu \mathrm{m}$ that then disassemble or disperse, with lifetimes of $\sim 60 \mathrm{~s}$ (Munro et al. 2004). These focal contractions are associated with and presumably drive local membrane invaginations. Movement of the sperm MTOC toward the cortex causes a rapid local cessation of focal contractility and an asymmetrical contraction of the remaining actomyosin network, causing a flow of cortical actomyosin toward the opposite (future anterior) pole. These flows transport Par-3/Par-6/Pkc-3, causing their 


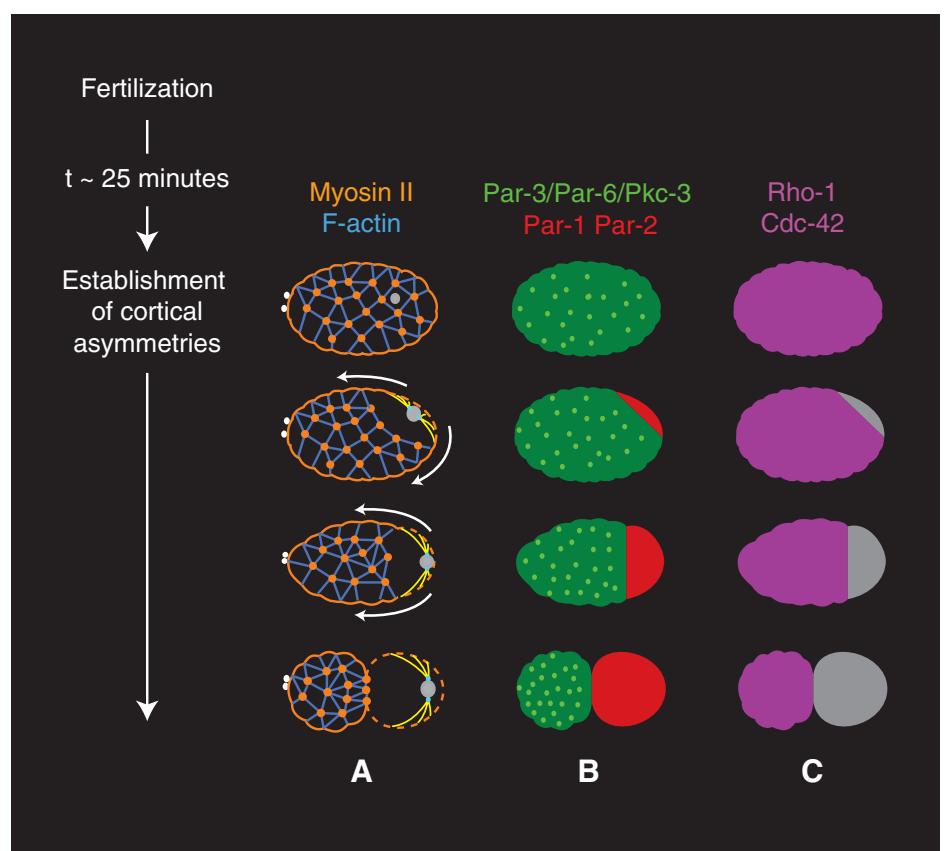

Figure 1. Cortical rearrangements underlying symmetry-breaking and polarity establishment in P0. $(A)$ The symmetry-breaking cue is associated with the microtubule organizing center (the sperm MTOC: Gray, nucleus; cyan, centrosomes; yellow, microtubules) that forms near the site of sperm entry at the end of meiosis $\sim 25$ min after fertilization. Near the end of meiosis, a cortical network containing F-actin (blue) and nonmuscle myosin II (orange) drives focal contractions and cortical ruffling. Signal(s) from the MTOC locally inhibit contractility, inducing asymmetrical contractions and cortical flow that segregate focal contractions and ruffling into an anterior cap bounded on the posterior by a deep transient furrow called the pseudocleavage furrow. (B) The same flow concentrates Par-3/Par-6/Pkc-3 (green) within the anterior cap, removing an inhibitory influence (see text and Fig. 2) that allows Par-1 and Par-2 (red) to concentrate within a complementary posterior domain. $(C)$ Cortical flows also segregate Rho-1 and Cdc-42, leading to their concentration within an anterior cap. Anterior is to the left in this and all subsequent figures.

enrichment within an anterior cap and their depletion from the posterior cortex. This in turn allows Par-1 and Par-2 to associate with the cortex in a complementary posterior domain. In addition to cross-regulating one another, the Par proteins also feedback to modulate actomyosin dynamics, cortical flows, and thus their own redistributions in ways that are still not well understood (Fig. 2).

How does the sperm cue work mechanically? One possibility is that it triggers the mechanical rupture of a prestressed cortical network, leading to the rapid discharge of stored mechanical stress. This type of mechanical instability is thought to drive symmetry breaking and directional motility of beads coated with agents that promote actin filament assembly in vitro (see van der Gucht and Sykes 2009 and Mullins 2009). It may also govern symmetry-breaking processes underlying directional actin-dependent motility of endosomes (Taunton et al. 2000), chromosomes (Li et al. 2008), and the episodic myosin-dependent collapse of the cell cortex that underlies shape oscillations in cellular fragments (Paluch et al. 2005).

However, acute mechanical rupture seems an unlikely explanation for symmetry breaking in $\mathrm{P}_{0}$. Direct observations fail to reveal a pronounced depletion of F-actin near the sperm MTOC. This is inconsistent with mechanical rupture of the actin network and suggests that new actin filaments must rapidly assemble to replace any that flow away from the sperm 


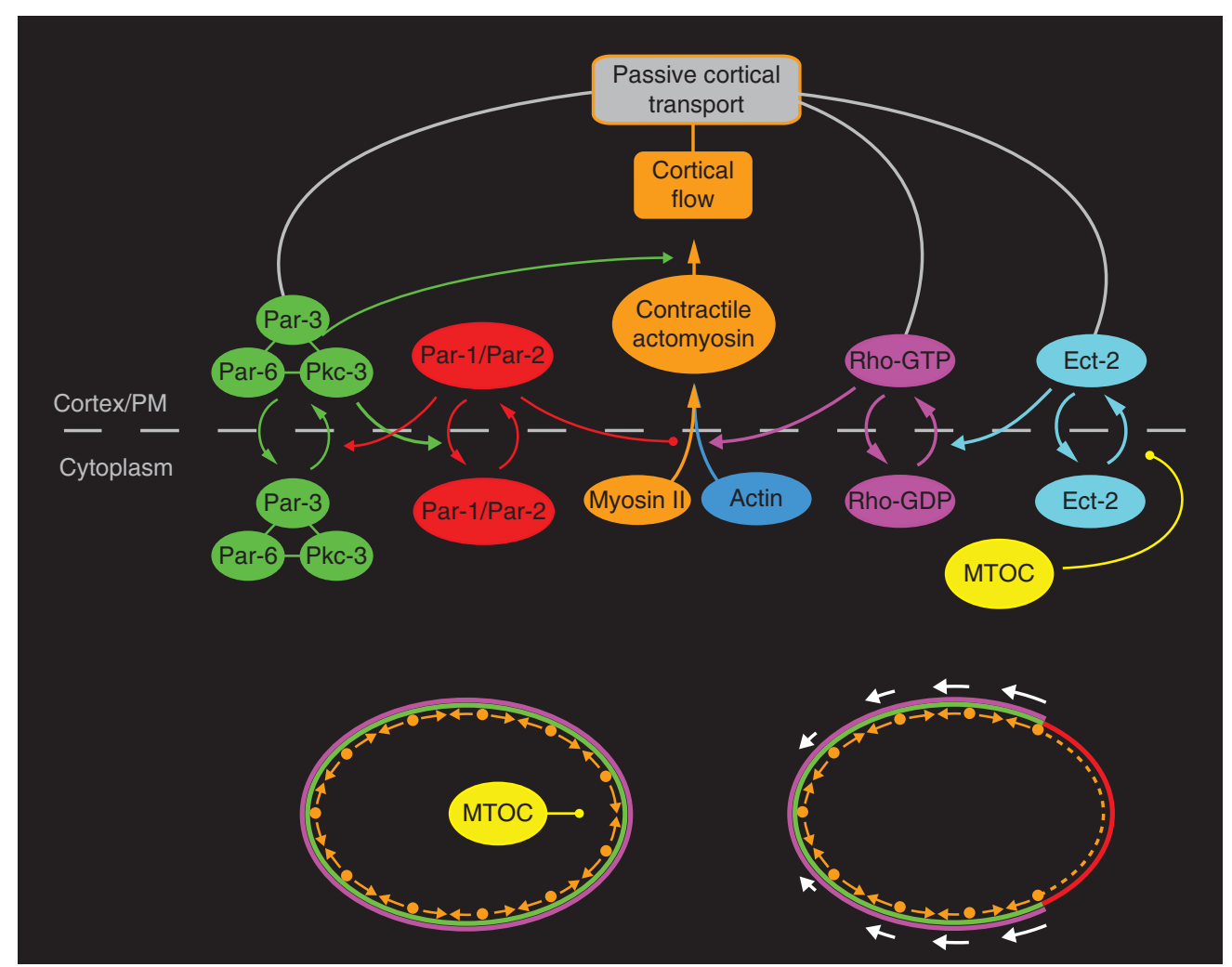

Figure 2. Feedback interactions underlying symmetry breaking during polarity establishment in P0. Par proteins and GTPases associate dynamically with the cortex/plasma membrane. F-actin and myosin II organize a contractile network that generates cortical flows, which transport actomyosin, Par-3/Par-6/Pkc-3, and small GTPases (only Rho-1 is shown here). The "anterior" and "posterior" Par proteins cross-inhibit one another's cortical association to help enforce complementarity. The Par proteins and small GTPases also feedback to modulate cortical contractility and thus their own redistribution.

MTOC. Likewise, focal contractions persist as the cortex flows toward the posterior (Munro et al. 2004). The average duration of a focal contraction $(\sim 60 \mathrm{~s})$ is short relative to the period of cortical flow $(\sim 8 \mathrm{~min})$, and the actin filaments and myosin II that accumulate locally during each contraction disappear rapidly when the contraction terminates. Thus the cortical actomyosin network turns over rapidly relative to the timescale of cortical flow, consistent with observations in other cells (Theriot and Mitchison 1992; Watanabe and Mitchison 2002). Such a network would dissipate stored elastic stress as its stress-bearing elementsactin filaments, cross-linkers, and myosin motors-turnover, and therefore should behave like a viscous material on timescales longer than the lifetimes of its elements. Therefore cortical flows that establish polarity probably represent the response of a viscous material to a persistent gradient of contractile tension, rather than the one-time discharge of a prestressed elastic material.

A likely source of this tension gradient is a sustained gradient of Rho activity. Indeed, several recent studies have shown that focal contractility and cortical flows require RhoA, and that the onset of cortical flows is associated with, and requires, a local inhibition of RhoA in the vicinity of the sperm MTOC (Jenkins et al. 2006; Motegi and Sugimoto 2006; Schonegg and Hyman 2006). This inhibition is associated with local cortical depletion of a Rho GEF called Ect-2 in the vicinity of the 
sperm cue (Motegi and Sugimoto 2006). Depletion of Ect-2 requires functional centrosomes, but not active contractility, making it a prime candidate for mediating the initial symmetry-breaking cue. It has also been suggested that this inhibition requires a Rho GAP called Cyk-4, whose activity may be localized by the deposition of paternally synthesized mRNA/protein during sperm entry (Jenkins et al. 2006).

\section{WHAT IS THE CUE?}

The identity of the cue(s) that trigger polarization, and whether this cue involves microtubules, has been an ongoing controversy. With the possible exception of Cyk-4/RhoGAP (Jenkins et al. 2006), mutants that fail in polarity establishment have turned out to encode maternally supplied factors associated with centrosome assembly and maturation (O'Connell et al. 2000; Hamill et al. 2002; Cowan and Hyman 2004b), and UV laser-induced ablation of centrosomes can prevent polarity establishment (Cowan and Hyman 2004). Thus centrosomes, or something closely associated with them, are required. However, the onset of polarization coincides with the outgrowth of a centrosomally nucleated microtubule array (the sperm aster), and thus it has been difficult to separate a requirement for centrosomes themselves from a requirement for the microtubule aster they produce. Indeed, several groups have shown that when meiosis fails or is slow to complete, the acentriolar meiotic spindle can induce the formation of reversed, but still complementary, distributions of the Par proteins, actomyosin, and some, but not necessarily all, cytoplasmic determinants (O'Connell et al. 2000; Wallenfang and Seydoux 2000; Sonneville and Gonczy 2004; Cowan and Hyman 2006; Tsai and Ahringer 2007). Initial studies of embryos depleted of $\beta$-tubulin by RNAi suggested that neither normal nor reversed polarity induction requires intact microtubules (Cowan and Hyman 2004b; Sonneville and Gonczy 2004). However, recent work from the Ahringer group documented a strong correlation between the presence and size of the sperm aster and the occurrence and kinetics of polarity establishment (Tsai and Ahringer 2007); zygotes with smaller asters took longer to establish cortical polarity. An attractive scenario is that centrosomes (or meiotic chromosomes in the case of polarity reversal) produce a polarity-inducing signal, and that microtubule arrays help to transmit that signal to the nearby cortex, suggesting that the aster is normally involved in transmitting a signal to the cortex, if not in producing that signal. Although it is also possible that microtubules could exert a direct mechanical effect on the cortex, this remains to be shown. Clearly, further progress in this area will depend on identifying molecular components of the cue beyond those factors required to form mature centrosomes and nucleate a sperm aster. These have not turned up thus far in genome-wide screens, perhaps because of pleiotropic or redundant gene requirements.

\section{A THRESHOLD FOR TRIGGERING POLARITY ESTABLISHMENT?}

Some symmetry-breaking systems require a polarizing cue. Others can spontaneously break symmetry in the absence of any cues, often by amplifying local stochastic fluctuations in the concentrations of participating molecules. In these cases, polarizing cues "choose" the axis of symmetry breaking. C. elegans zygotes in which centrosomes are ablated genetically (Munro et al. 2004) or with a UV laser (Cowan and Hyman 2004b) show normal focal contractility but do not spontaneously break symmetry. Local cortical flows associated with focal contractions imply local gradients of cortical tension (i.e., that spaces between foci represent "weak spots"), and yet these do not spontaneously self-amplify to produce global contractile asymmetry. This suggests that there is a threshold level of inhibition that the cue must exceed to trigger symmetry breaking. This could either be a threshold in the inhibition domain size, the duration of inhibition, or both. In wild-type embryos, polarity establishment is associated with the appearance and progressive growth of a smooth posterior domain, which lacks focal contractions and 
cortical ruffling and contains high levels of Par-2. Interestingly, when centrosomes are laser-ablated after the smooth domain has formed, the domain continues to grow-again supporting the existence of a threshold (Cowan and Hyman 2004b).

What is the nature of this threshold? Growth of the smooth domain coincides with a progressive depletion of both Rho and Ect-2/ RhoGEF from the posterior (Jenkins et al. 2006; Motegi and Sugimoto 2006), implying the growth of a zone of relative myosin inactivity. This depletion itself depends on myosin contractility and cortical flow, implying a feedback loop: Local inhibition/depletion of Rho promotes cortical flows that transport Ect-2 and Rho away from the posterior, leading to the further growth of a zone of Rho depletion/inhibition (Fig. 2). Likewise, in wild-type embryos, the smooth Par-2-rich domain grows progressively during polarity establishment. Previous work suggests that Par-2 acts locally to inhibit myosin II recruitment (Munro et al. 2004), again implying a feedback loop: Local accumulation of Par-2 promotes contractile asymmetries that drive flows and transport factors (Par-3/Par-6/ Pkc-3) that inhibit Par-2 accumulation, thus promoting growth of an inhibitory Par-2 domain.

These observations suggest the attractive possibility that the threshold for triggering a self-amplifying asymmetry is associated with the formation kinetics of local Rho-depleted and/or Par-2-rich/myosin inhibitory domains. Simple mathematical analyses show that such feedback loops could endow the cortex with a threshold response (Munro et al. unpublished). Whether or not they actually do so depends on quantitative details: Cortical flow speeds will depend on the relative magnitudes of contractile forces that drive cortical flow and the effective viscous resistance to flow; cortical exchange rates for key factors and the efficiency of their coupling to cortical flow will jointly determine how rapidly cortical flows either concentrate inhibitors (Par-2) or deplete activators (Rho/ Ect-2), and whether and how rapidly this zone of inhibition becomes self-amplifying.
Measuring these quantities should be an important goal for future studies.

Like Rho, the small GTPase Cdc- 42 becomes anteriorly enriched during polarity establishment in a manner that depends on cortical flows (Fig. 1C) (Aceto and Kemphues 2006; Motegi and Sugimoto 2006; Schoenegg and Hyman 2006). Cdc-42 is subsequently required to maintain cortical actomyosin and Par protein asymmetries (Gotta et al. 2001; Aceto and Kemphues 2006; Schonegg and Hyman 2006; Motegi and Sugimoto 2006, Velarde et al. 2007). However, Cdc-42's role in polarity establishment itself has been less clear, in part because of a difficulty in assessing the complete loss of function phenotype. Unlike for Rho, strong depletions of Cdc-42 only weakly effect cortical flow during polarity establishment, but strongly inhibit cortical recruitment of Par-6/Pkc-3 (Motegi and Sugimoto 2006; Schonegg and Hyman 2006; Aceto and Kemphues 2006). Thus Cdc-42 may be involved, at least indirectly, in coupling cortical flows and Par protein transport (Schonegg and Hyman, 2006), but how this works physically remains to be determined.

\section{WHAT POSITIONS AND STABILIZES THE AP BOUNDARY?}

A key feature of polarization in $\mathrm{P}_{0}$ is that the response to the sperm cue is self-limitingrather than contract itself right off the end of the egg, the asymmetrical contraction "stalls" about halfway across to form stable anterior and posterior domains. How might this work? Studies in a variety of cells suggest that crossinhibitory interactions between anterior (Par-3/Par-6/Pkc-3) and posterior (Par-1/ Par-2) Par proteins implement a kind of winner-take-all competition, in which either Par-3/Par-6/Pkc-3 or Par-1/Par-2, but not both, can occupy the cortex locally (Benton and St Johnston 2003; Hao et al. 2006; reviewed in Munro 2006). Such a mechanism could dynamically maintain a local boundary between complementary anterior and posterior Par domains. By transporting Par-3/Par-6/Pkc-3, cortical flows would tend to move this 
boundary toward the anterior. Thus the position of the boundary will be shaped by the magnitude and extent of cortical flow. Indeed, inhibiting contractility during polarity establishment causes the AP Par boundary to shift to the posterior (Shelton et al. 1999; Cuenca et al. 2003), whereas increasing Rho activity and presumably contractile forces causes the boundary to shift to the anterior (Schmutz et al. 2007; Schonegg et al. 2007). Interestingly, if centrosomes are ablated after a symmetrybreaking threshold is reached, then the AP boundary never extends as far as it does in a wild-type embryo; if the boundary has reached its maximal extent before ablation, then it shifts back posteriorly (Cowan and Hyman 2004b). This suggests that a persistent local inhibition of contractility near the sperm cue may also contribute to positioning the boundary.

However, biasing the strength of contractility cannot alone explain the ability of the cortex to adopt a stable boundary position. A mechanically stable position for the AP boundary implies either an absence of force or a balance of equal and opposite forces. If the anterior cortex is more contractile than the posterior cortex, as implied by the asymmetric distribution of myosin II, focal contractility, and cortical ruffling, then some other mechanism must supply a balancing force. One general possibility is that the anterior and/or posterior cortex contains elastic or viscoelastic material that passively resists deformation. Initially, the contractile forces must dominate resistive forces to allow symmetry breaking to occur, but then either the resistive force must increase, or the difference between anterior and posterior contractile forces must attenuate, as the anterior domain contracts and the posterior domain expands. There are many variants of this scenario, and it is premature to speculate on the underlying molecular mechanisms. Significantly, mutating anterior Par proteins leads to a posterior shift in the AP boundary, whereas mutating posterior Par proteins leads to a posterior shift in par-2 mutants and an anterior shift in par-1 mutants (Kirby et al. 1990; Cuenca et al. 2003; Munro et al. 2004; Velarde et al. 2007). Thus in addition to cross-inhibitory interactions, the Par proteins must feedback to regulate the balance of cortical forces and their own redistribution. The nature of this feedback is not yet known, but a mechanistic explanation of how the zygote converts local inhibition of contractility into a pair of stable cortical domains must integrate a system of feedback loops involving the interplay between local biochemical regulation, cytoskeletal dynamics, and cytomechanics.

\section{CORTICAL ACTOMYOSIN SYMMETRY BREAKING DURING CYTOKINESIS}

Recent work highlights interesting parallels between polarization of the anterior-posterior axis and cleavage furrow specification in $\mathrm{P}_{0}$. During cytokinesis, the mitotic apparatus signals to the cell cortex to specify the site of contractile ring assembly. In $\mathrm{P} 0$, this involves two classically defined modes of signalingequatorial stimulation and polar relaxation. The key pathway for equatorial stimulation involves the highly conserved centralspindlin complex, formed by a kinesin-6 motor (Zen-4/Mklp-1) and a Rho GAP (Cyk-4/ MgcRAC-GAP). In many other cells, centralspindlin locally activates the Rho GEF (Ect-2/ RhoGEF) to specify an equatorial zone of high Rho activity (Somers and Saint 2003; Yuce et al. 2005; Nishimura and Yonemura 2006). The molecular mechanisms underlying polar relaxation have been more elusive, but recent work in C. elegans (Werner et al. 2007) and other cells (Foe and von Dassow 2008; Murthy and Wadsworth 2008) points to a key role for astral microtubules in shaping the distribution of signal(s) that locally inhibit Rho-dependent myosin recruitment/activation at anaphase, biasing cortical contractility to the equator, where the density of astral microtubule plus ends may be low (Deschant and Glotzer, 2003).

In C. elegans, the astral and central spindle pathways function redundantly during normal cytokinesis, but it has been possible through physical, genetic, and pharmacological manipulations to isolate and resolve their individual actions within the same cell (Hird and White 1993; Bringmann and Hyman 2005; Motegi 
et al. 2006; Bringmann et al. 2007; Werner et al. 2007; Baruni et al. 2008). Studies of cortical actomyosin dynamics and furrowing in these manipulated embryos reveal parallels between cortical responses to astral signals during furrow induction and the sperm cue during polarity establishment (Fig. 3) (Hird and White 1993; Werner et al. 2007). In wild-type C. elegans embryos, and in mutant embryos lacking functional centralspindlin, anaphase onset coincides with a burst of cortical myosin recruitment (Werner et al. 2007). This recruitment is biased to regions that are relatively devoid of microtubule plus ends-the anterior cortex and a broad equatorial domain that prefigures the contractile ring (Fig. 3C) (Dechant and Glotzer 2003; Werner et al. 2007) —and newly recruited myosin concentrates within foci that are similar in size and spacing to those observed during polarity establishment. When partial inhibition of astral microtubule assembly leads to the formation of a small posteriorly localized spindle, anaphase myosin recruitment occurs everywhere except in a region surrounding the posterior spindle
(Fig. 3E). This is followed by an asymmetric contraction of the cortex, cortical flows, and the formation of a single transient deeply ingressing anterior furrow that resembles, at least superficially, the pseudocleavage furrow that forms during polarity establishment (Werner et al. 2007). Interestingly, cortical flows and furrowing in response to the sperm MTOC cue and to posteriorized spindles at anaphase share similar requirements for Rho and Ect-2, and similar dependencies on factors that regulate myosin II activity (e.g., let-502/Rho Kinase and Mel-1l/phosphatase) or actin assembly (Cyk-1/ Formin) downstream of Rho. Moreover, perturbations that inhibit pseudocleavage or anterior furrow formation in embryos with posteriorized spindles also inhibit furrowing during normal cytokinesis in embryos lacking Zen-4 (Bringmann et al. 2007; Werner et al. 2007).

These data suggest that underlying normal cytokinesis, as proposed by White and Borisy more than 25 years ago (White and Borisy 1983), is an ability of the actomyosin cortex to amplify crude asymmetries imposed by astral inhibition into more sharply focused zones of

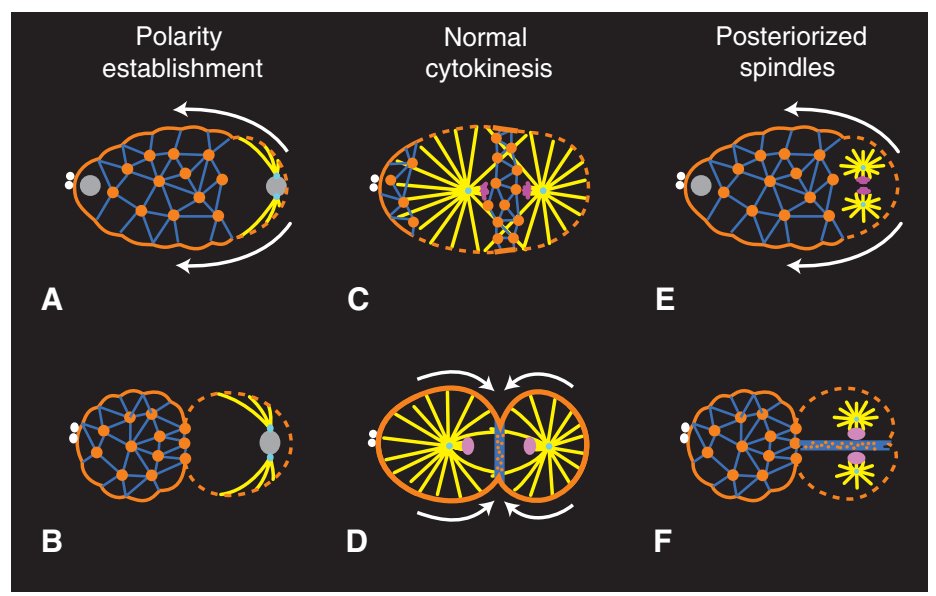

Figure 3. Similarities between polarity establishment, normal cytokinesis, and cytokinesis in embryos with posteriorized spindles. (A) During polarity establishment, signals from the sperm aster inhibit focal actomyosin contractions, triggering cortical flows that result $(B)$ in formation of an actomyosin-rich anterior cap, bounded by a single deep transient pseudocleavage furrow. $(C, D)$ At anaphase in wild-type embryos, myosin-rich foci accumulate in regions that are relatively devoid of astral microtubules-on the extreme anterior cortex, and in an equatorial zone that prefigures the contractile ring. $(D)$ As furrowing proceeds, cortical flows carry cortical material toward and into the deepening furrow. (E) At anaphase in embryos with posteriorized spindles, astral signals inhibit accumulation of myosin-rich foci at the posterior cortex, resulting in cortical flows, formation of an anterior cap, and formation of a single transient "cleavage furrow." $(F)$ A second centralspindlin-dependent furrow forms midway between the mitotic asters. 
Cellular Symmetry Breaking during Caenorhabditis elegans Development

contractile activity. In wild-type embryos, this ability is supplemented by direct equatorial stimulation via the central spindle pathway. Although Borisy and White envisioned amplification through flow-mediated reorientation of cortical microfilaments, it is also possibleperhaps more likely-that amplification is mediated through cortical transport of factors (e.g., Ect-2/GEF, RhoA, Anillin, Cyk-1/ formins) that promote local myosin recruitment/activation or actin filament assembly and cross-linking.

\section{SYMMETRY BREAKING AND \\ ESTABLISHMENT OF SIMPLE APICO-BASAL POLARITY IN EARLY SOMATIC BLASTOMERES}

The asymmetric division of $\mathrm{P}_{0}$ is the first in a series of four asymmetric divisions, each of which produces one daughter that contributes only to soma, and another that produces the germline. Interestingly, the Par proteins segregate into complementary domains before each of these divisions (Fig. 4A-C) (Boyd et al. 1996; Etemad-Moghadam and Kemphues 1995; Guo and Kemphues 1995; Hung and Kemphues 1999; Tabuse et al. 1998). At least for the second germline precursor division (of P1) (see Fig. 4B), this is preceded by a movement of the centrosomes and nucleus of P1 toward the posterior pole, and is accompanied by cortical flows of actomyosin and Par-3/ Par-6/Pkc-3 toward the opposite anterior pole (Hird and White 1993; Munro et al. 2004), suggesting a reiterative use of the same symmetrybreaking mechanisms.

In contrast, beginning at the four-cell stage, the somatic daughters manifest a new asymmetry in which Par-1 and Par- 2 accumulate on

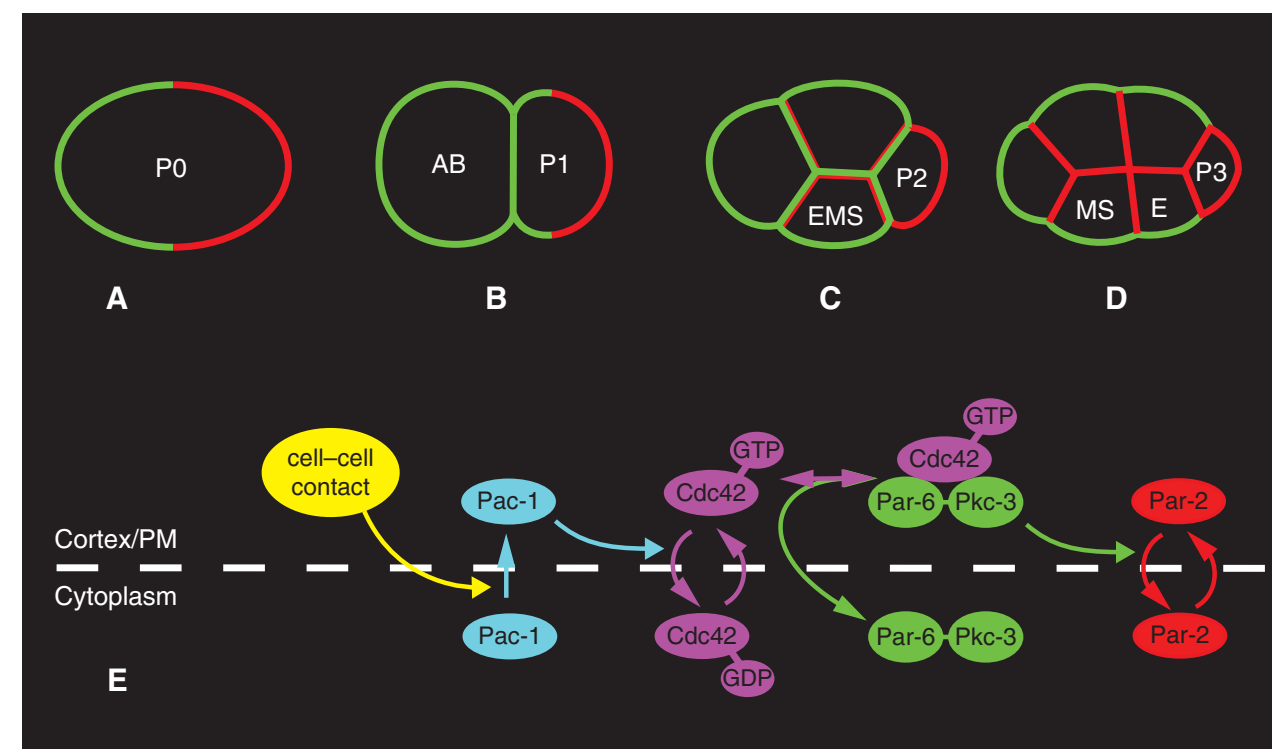

Figure 4. Establishment of apico-basal Par asymmetries on somatic blastomeres. $(A-D)$ Schematic overview of Par asymmetries in early blastomeres. In the one-cell $(A)$ and two-cell $(B)$ stages, Par1/Par2 are enriched on the posterior cortex of germline precursors $\mathrm{P} 0$ and $\mathrm{P} 1$, whereas Par-3/Par-6/Pkc-3 are enriched on the anterior cortex. At the early four-cell stage $(C)$, Par-1/Par-2 are enriched in newly born somatic blastomeres on domains of cell-cell contact and at the cortex of the germline precursor P2, whereas Par-6/Pkc-3 are enriched on all somatic cell boundaries. By the seven-cell stage $(D)$, Par-6/Pkc-3 have disappeared from domains of somatic cell contact. (E) A pathway for establishment of apico-basal polarity downstream of cell-cell contact (based on Anderson et al. 2008). The Rho GAP Pac-1 accumulates on somatic cell-cell contacts, where it promotes the conversion of Cdc- 42 from an active membrane-bound to an inactive cytoplasmic form. Removal of Cdc- 42 from cell contacts results in a loss of cortical Par-6/Pkc-3; this in turn allows Par-1/Par-2 to accumulate at somatic cell-cell contacts (see Anderson et al. 2008 for details). 
"basolateral" domains of contact between adjacent blastomeres, whereas Par-3/Par-6/Pkc-3 accumulate on the outer noncontacting "apical" domains (Nance and Priess 2002). Failure to properly establish and maintain these asymmetries is associated with defects in the ingression of endoderm progenitors during early gastrulation (Nance et al. 2003). Blastomere isolation and recombination experiments showed that these asymmetries depend on, and can be induced by, cell-cell contacts. As in P0, Par-3/Par-6/Pkc-3 are required to exclude Par-1 and Par-2 from noncontacting surfaces (Nance and Priess 2002; Nance et al. 2003). However, whereas removal of Par-1 or Par-2 results in loss of cortical Par-3/Par-6/ $\mathrm{Pkc}-3$ asymmetries in $\mathrm{P} 0$, it has no discernible effect on these later apico-basal asymmetries of Par-3/Par-6/Pkc-3.

Recently, a Rho-GAP called PAC-1 was identified that accumulates specifically on surfaces of cell-cell contact and is required for apico-basal asymmetry (Anderson et al. 2008). In pac-1 mutants, Par asymmetries in $\mathrm{P}_{0}$ are normal but in somatic blastomeres Par-3/ Par-6/Pkc-3 are uniformly cortical, whereas Par-2 and Par-1 are absent from domains of cell-cell contact. Although Pac-1's Rho GAP domain has activity toward Rho, Rac-1, and Cdc-42 in vitro, it appears to act through Cdc-42. Loss of Cdc- 42 in somatic blastomeres results in complete loss of Par-6/Pkc-3 from, and the accumulation of Par- 2 onto, domains of cell-cell contact. Expressing a constitutively active form of Cdc- 42 in the same cells forces accumulation of Par-6/Pkc-3 (and loss of Par-2) at cell-cell contacts without affecting Pac-1 localization. This latter effect depends on a semi-CRIB domain in Par-6 that mediates binding of Par-6 to active Cdc-42 (Aceto et al. 2006). Together, these data support a model in which Pac-1 inactivates Cdc-42, releasing Par-6/Pkc-3 from cell-cell contacts, and thus allowing Par-1 and Par-2 to accumulate there (Fig. 4E).

How Pac-1 accumulates specifically at cellcell contacts, and how Pac-1 excludes Par-3 from cell-cell contacts, remains unclear because removal of Cdc-42 (at least in the zygote) does not abolish cortical localization of Par-3 (Gotta et al. 2001; Beers and Kemphues 2006). One possibility is that Pac-1 acts through additional GTPases, such as Rho itself. Interestingly, the establishment of apicobasal polarity is accompanied by cortical flows of actomyosin toward the center of the apical domain where Par-3/Par-6/Pkc-3 become concentrated (Gotta et al. 2001; Nance et al. 2003; Munro et al. 2004). Thus in principle, cortical flows triggered by local inhibition of Rho could establish Par-3 asymmetries as observed in the zygote, but this remains to be tested. In summary, the establishment of apico-basal polarity in somatic cells appears to use a different cue but an overlapping set of molecules and interactions, compared with anteriorposterior polarity establishment in $\mathrm{P}_{0}$.

\section{APICO-BASAL SYMMETRY BREAKING IN EMBRYONIC AND POSTEMBRYONIC EPITHELIA}

The mechanisms that establish apico-basal polarity in C. elegans epithelia are beginning to receive attention (Labouesse 2006). Epithelial structures in C. elegans include the gastrointestinal tube that runs the length of the body and the spermatheca, a polarized epithelium that forms a highly distensible valve and links each gonadal arm to a common uterus in the adult hermaphrodite (reviewed in Hubbard and Greenstein 2000; Schneider and Bowerman 2003). Sperm reside in the spermatheca, and oocytes sequentially transit through them during ovulation and fertilization. Finally, the embryonic epidermis polarizes and ultimately encloses the embryo, after the completion of most cell proliferation at the so-called bean stage. Contractile forces generated by the actomyosin cytoskeleton within the epidermis then promote the morphogenetic squeezing and elongation of an initially oval mass of embryonic cells into a long, thin worm (Priess and Hirsh 1986).

In each of these polarized C. elegans epithelia, we are only beginning to identify mechanisms that break symmetry during the establishment of apico-basal polarity. Proper 
junction formation in the intestine and some, but not all, aspects of apico-basal polarity require PAR-6 (Totong et al. 2007). Polarized organization of the cytoskeleton within, and attachment of pharyngeal epithelial cells to the epidermal surface at the mouth of the worm, requires a RhoGAP and a kinesin, CYK-4 and ZEN-4, respectively (Portereiko et al. 2004), which form the "centralspindlin" complex known previously only for requirements during cytokinesis (see previous discussion). In the spermatheca, C. elegans orthologs of Scribble and Discs Large, required for neuroblast polarity in Drosophila (see Prehoda 2009), are required for the apical polarization of PAR-3 (Pilipiuk et al. 2009), and loss of PAR-3 causes ovulation defects (Aono et al. 2004). Finally, although genetic investigations of embryonic morphogenesis in C. elegans have improved our understanding of epidermal structural integrity, the mechanism of epidermal polarization, and how polarization influences epithelial integrity, remains poorly understood. With the exception of $C$. elegans LET-413/Scribbled, known polarity regulators that act elsewhere in the embryo are not expressed or required in the embryonic epidermis (LaBouesse 2006). However, roles for PAR-3 and PAR-6 within intestinal and spermathecal cells were only recently discovered (Aono et al. 2004; Anderson et al. 2008) using more targeted approaches to inactivate gene products at specific times and places during development. These roles are conserved in mammalian epithelia (see Nelson 2009; McCaffrey and Macara 2009), and as additional mutant alleles and genetic tools become available we should learn more about symmetry breaking in C. elegans epithelia.

\section{REITERATIVE POP-1 ASYMMETRY AND $\beta$-CATENIN MEDIATED BINARY SPECIFICATION}

As discussed previously, the PAR proteins control an early sequence of asymmetric cell divisions that each segregate germline from the soma. Partway through this sequence, another mechanism that relies on the differential localization and activation of Wnt signaling pathway components makes daughter cells different. This mechanism is first used at the 4-cell stage to distinguish endoderm from mesoderm. It then continues to influence sister cell fate distinctions throughout somatic development, whenever a cell divides at least in part along the anterior-posterior (AP) body axis. We refer to this process as reiterative binary specification, as it repeatedly mediates the binary distinction of anterior versus posterior sister cell fates throughout embryonic and larval development (Kaletta et al. 1997; Huang et al. 2007).

As nearly all C. elegans cell divisions occur with mitotic spindles aligned along the AP axis (Sulston and Horvitz 1977; Sulston et al. 1983), the single mechanism of binary specification apparently influences nearly every cell fate decision made during $C$. elegans development. Extensively studied examples include the embryonic induction of endoderm, and asymmetric larval cell divisions of the somatic gonad precursors and tail neuroblasts called $\mathrm{T}$ and $\mathrm{B}$ (reviewed in Mizumoto and Sawa 2007). Additional studies indicate that this mechanism appears to influence nearly every AP sister cell fate distinction made during embryonic and larval development (Lin et al. 1995; Kaletta et al. 1997; Lin et al. 1998; Meneghini et al. 1999; Park and Priess 2003; Huang et al. 2007; Bertrand and Hobert 2009). The extent of this influence was most clearly revealed by use of a temperaturesensitive mutation in the conserved kinase LIT-1/NLK to inactivate binary specification. After temperature up shifts at any time after the four-cell stage, all posterior cell fates were lost in all embryonic somatic cell lineages (Kaletta et al. 1997).

The ultimate target and mediator of binary specification is a TCF related transcription factor encoded by the C. elegans gene pop-1. More generally, TCFs are the targets of Wnt signal transduction (Nusse 2005). In C. elegans, a Wnt signal at the four-cell stage induces the first asymmetry in POP-1 levels at the seven-cell stage, and this asymmetry is required for endoderm fate (reviewed in Thorpe et al. 2000). Briefly, the posterior-most 
blastomere in a four-cell stage embryo, called $\mathrm{P}_{2}$, produces MOM-2/Wnt ligand that polarizes its ventrally positioned sister, EMS (see Fig. 4C). As a result, nuclear POP-1 levels are lower in E, the posterior daughter of EMS, which adopts an endoderm fate, and higher in its anterior daughter MS, which adopts a mesoderm fate (see Fig. 4D and Fig. 5A). In the absence of Wnt signaling from P2, POP-1 levels are high in both EMS daughters, and both adopt mesoderm fates, at the expense of endoderm. Beyond the 4-cell stage, whenever wild-type embryonic or larval cells divide at least in part along the AP axis, POP-1 levels are again high and low in daughter nuclei pairs (Lin et al. 1995; Lin et al. 1998), with low nuclear POP-1 levels promoting posterior fates, and high levels promoting anterior fates. In some larval lineages, the axis of polarity is altered such that POP-1 levels are low in proximal and high in distal daughters, relative to the position of the vulva midway along the anterior-posterior larval axis.

Multiple Wnt pathway components and modulators shape the establishment of POP-1 asymmetries and their functional consequences (Mizumoto and Sawa 2007). One modulator that acts reiteratively throughout development is a MAP Kinase-related protein encoded by the lit-1 gene (Kaletta et al. 1997; Meneghini et al. 1999; Rocheleau et al. 1999). In lit-1 mutants, nuclear POP-1 levels are high in both daughters of all AP divisions, and in all cases examined both daughters adopt anterior fates (Kaletta et al. 1997). More recently, vertebrate orthologs of LIT-1 (called NLKs) also have been shown to modulate Wnt signaling (Thorpe and Moon 2004).

In conjunction with LIT-1, two highly diverged $\beta$-catenins called WRM- 1 and SYS- 1 also act reiteratively throughout development to influence the levels and transcriptional activity of POP-1 (Mizumoto and Sawa 2007). Both WRM-1 and SYS- 1 are enriched in posterior daughter cell nuclei after all AP cell divisions, complementary to the enrichment of POP-1 in anterior daughter nuclei (Nakamura et al. 2005; Takeshita and Sawa 2005; Huang et al. 2007; Phillips et al. 2007), leading to use of the term Wnt/ $\beta$-catenin asymmetry as an alternative to binary specification (Mizumoto and Sawa 2007). As with POP-1 (see the following section), at least some of these asymmetries depend on Wnt ligands. WRM-1, in a complex with POP-1 and LIT-1, promotes the phosphorylation and nuclear export of POP-1, lowering its levels in posterior daughters (Meneghini et al. 1999; Rocheleau et al. 1999). The "limiting coactivator" SYS-1, in more typical $\beta$-catenin fashion, binds to and converts the remaining posterior nuclear POP-1 molecules into transcriptional activators (Siegfried et al. 2004; Kidd et al. 2005; Lam et al. 2006; Huang et al. 2007). Higher POP-1 levels in anterior daughter nuclei overwhelm the limited SYS-1 levels and repress genes activated by POP-1/SYS-1 in posterior daughters. Thus low nuclear POP-1 levels in posterior daughters helps to convert POP-1 into an activator, whereas high levels result in POP-1 acting as a repressor. Such dual regulation of TCF levels and function by two different $\beta$-catenins is thus far unique to $C$. elegans and perhaps other nematodes.

\section{Upstream Cues}

The first example of POP-1 asymmetry involves Wnt signaling from the posterior blastomere $\mathrm{P}_{2}$ (Thorpe et al. 2000). In a similar fashion, WNT signaling from P2 and its descendants induce subsequent POP-1 asymmetries in anterior somatic AP sister-cell pairs until at least the 28-cell stage (Lin et al. 1998; Meneghini et al. 1999; Park and Priess 2003). POP-1 asymmetries in the daughters of the larval somatic gonad precursor cells, and of several larval tail neuroblasts, also require Wnt ligands (Takeshita and Sawa 2005).

However, Wnt ligands may not be directly required for all POP-1 asymmetries. Inactivation of the Wnt receptor MOM-5/ Frizzled results in a loss of POP-1 asymmetry throughout embryogenesis. By contrast, in the absence of a Wnt ligand, POP-1 asymmetry is lost only until the 28-cell stage: Remarkably, POP-1 asymmetries re-emerge by the 50-cell stage in most mutant embryos (Park and 
Priess 2003). Analogous results come from studies in which anterior embryonic cells are prevented from receiving Wnt signals from neighboring cells by sequential isolation at birth (Park and Priess 2003). Early in their development, such repeatedly isolated anterior cells fail to produce POP-1 asymmetry, indicating a requirement for a Wnt signal. But later in their development, the isolated anterior cell lineages acquire, by what would be roughly the 50-cell stage for intact embryos, an intrinsic ability to manifest high/low POP-1 asymmetry in sister cell pairs. This more intrinsic mechanism requires a Frizzled receptor but not Wnt ligands. Intriguingly, the distribution of Frizzled itself is polarized in these later embryonic cells, enriched at the posterior cortex (Park et al. 2004). The polarized distribution of, and the Wnt-independent requirement for Frizzled are reminiscent of planar cell polarity in Drosophila epithelia (see Vladar et al. 2009). However, no planar cell polarity specific orthologs appear to influence embryonic POP-1 asymmetries (Park and Priess 2003).

Wnt Signaling and Mitotic Spindle Orientation

Loss of Wnt signaling in the early embryo results not only in losses of POP-1 asymmetry, but also in abnormal spindle orientations in embryonic cells, beginning at the four-cell stage in EMS (Schlesinger et al. 1999; Park and Priess 2003; Hawkins et al. 2005; King et al. 2009). Thus POP-1 asymmetry appears to be coordinated with proper mitotic spindle orientation. Indeed, both $\mathrm{P}_{2}$ and its daughters are competent for Wnt signaling and both can induce POP-1 asymmetry and orient mitotic spindles in reconstructed partial embryos (Park and Priess 2003; Bischoff and Schnabel 2006). Moreover, Wnt ligand alone attached to beads is sufficient, in the presence of another permissively acting signal, to both orient the mitotic spindle in EMS, and induce POP-1 asymmetry in the daughters of EMS (Goldstein et al. 2006). Finally, one recent study concludes that a persistent posterior center produces Wnt ligand throughout embryogenesis, acting through a
Frizzled receptor-dependent relay mechanism to orient all anterior cell divisions along the embryonic AP axis (Bischoff and Schnabel 2006). Whether or not such a persistent posterior Wnt signaling center also influences POP-1 asymmetry in later stage embryos is unknown, but these two responses in EMS and other early embryonic cells appear to be coordinated by positionally restricted Wnt ligand cues. The origin of this posterior center is not known but may be established by Par proteins in the early embryo.

These different studies suggest that a temporal change occurs in the mechanisms that establish POP-1 asymmetries and align them along the AP axis. Early on, both POP-1 asymmetry and mitotic spindle orientation require a Wnt ligand called MOM-2. However, after the 28-cell stage anterior lineages begin to acquire an intrinsic, Frizzled-dependent ability to generate POP-1 asymmetry. Indeed, in mom-2/Wnt(-) mutant embryos the later POP-1 asymmetries are properly oriented with respect to the AP axis, even though the exact positions of these embryonic cells are abnormal. Nevertheless, directional cues from Wnt signaling centers may still act to align POP-1 asymmetries and mitotic spindles along the AP axis. Intriguingly, another Wnt ligand, CWN-1, and the Wnt pathway cytoplasmic factor DSH-2/Dishevelled, were recently shown to be required for proper specification of multiple embryonic neuronal cell fates produced by asymmetric cell divisions (Hawkins et al. 2005; King et al. 2009). Wnt signaling also influences mitotic spindle orientation during postembryonic development of the vulval precursors cells P5.p and P7.p (Green et al. 2008), with multiple Wnt ligands and receptors required to properly pattern the orientations of these divisions. Thus multiple studies point toward widespread requirements for Wnt signaling throughout C. elegans embryogenesis to regulate binary specification and mitotic spindle orientation. Nevertheless, it remains unclear how POP-1 asymmetries in later stage mom-2/Wnt mutant embryos are all properly oriented such that nuclear POP-1 levels are higher only in anterior sister cells (Park and Priess 2003). 


\section{The Evolution of Binary Specification}

Upstream cue(s) aside, the regulation of POP-1 asymmetry and binary specification in C. elegans seems byzantine. Indeed, nematodes are the only animal phylum with multiple $\beta$-catenin genes, and the nematode $\beta$-catenins are extremely diverged in amino acid sequence; most animal genomes encode a single $\beta$-catenin, although vertebrates encode one additional $\beta$-catenin homolog called plakoglobin (Schneider et al. 2003). Adding another input to an already complex process, a nuclear hormone receptor was recently shown to influence binary specification (Asahina et al. 2006). Moreover, asymmetric division of the male tail neuroblast B requires a Wnt ligand, a Frizzled receptor, and POP-1, but appears not to require $\beta$-catenin regulation, and to weakly require Drosophila planar cell polarity orthologs (Wu and Herman 2006; Wu and Herman 2007). Furthermore, both Wnt signaling and the planar cell polarity protein Vang-1 modulate binary specification and mitotic spindle orientation during the specification of vulval precursor cell fates in developing larvae (Green et al. 2008). Thus multiple inputs can influence binary specification. The evolutionary advantage of this complicated regulatory process is not obvious: Why establish a single regulatory module, with multiple upstream inputs and a presumably extensive promoter response network, to influence nearly every cell fate decision made during development?

The answer to this evolutionary puzzle may reside within the recent discovery of a remarkably similar $\beta$-catenin mediated binary specification mechanism in another animal phylum (Schneider and Bowerman 2007). During the asymmetric, spirally patterned embryonic cell divisions of the polychaete annelid Platynereis dumerilii, a well conserved $\beta$-catenin accumulates to high levels in all vegetal pole daughter nuclei, and to low levels in all animal pole daughter nuclei. High $\beta$-catenin levels are required reiteratively throughout Platynereis embryogenesis to specify vegetal, rather than animal, sister cell fates. This is remarkably similar to the distribution of and requirements for WRM-1 and SYS-1 in C. elegans, with the Platynereis animal/vegetal axis corresponding to the C. elegans anterior/posterior axis. It is not known whether Platynereis TCF levels are asymmetric in a complementary pattern, as for POP-1 in C. elegans. But Platynereis appears to encode only a single well-conserved $\beta$-catenin, which presumably functions to convert TCF into a transcriptional activator that specifies vegetal sister cell fates. Thus there may be no need for TCF asymmetry in Platynereis. In summary, although it is not known if binary specification in Platynereis includes TCF asymmetries, $\beta$-catenins in both Platynereis and $C$. elegans are repeatedly enriched in vegetal and posterior daughter cell nuclei, respectively, and required for their fates throughout embryogenesis.

Given the discovery of $\beta$-catenin-mediated binary specification systems in two distantly related animal phyla, one wonders whether binary specification might have an ancient evolutionary origin, or instead be an example of evolutionary convergence. A new report favors the latter possibility (Henry et al. 2008). In Cerebratulus lacteus, a member of the protostome phylum called nemerteans, $\beta$-catenin is detectable only in the most vegetal pole embryonic cell nuclei, with no evidence for reiterative sister cell differences in most lineages. This distribution closely resembles the pattern seen in sea urchin and chordate embryos (Fig. 5B) (Schneider et al. 1996; Larabell et al. 1997; Logan et al. 1999). Although the early embryos of more animal phyla should be examined, highly reiterative binary specification by $\beta$-catenin and TCF is limited thus far to C. elegans and Platynereis.

Perhaps the rapid, invariant cell divisions in these nematode and polychaete embryos benefit from an additional regulatory layer that reiteratively reinforces asymmetric sister cell fate decisions. The idea that POP- 1 asymmetry provides such a backup mechanism is perhaps consistent with the different degrees to which the SYS- 1 conversion of POP-1 into an activator is required for different AP sister-cell fate distinctions. POP-1 appears to act largely as a repressor during the specification of endoderm in the 


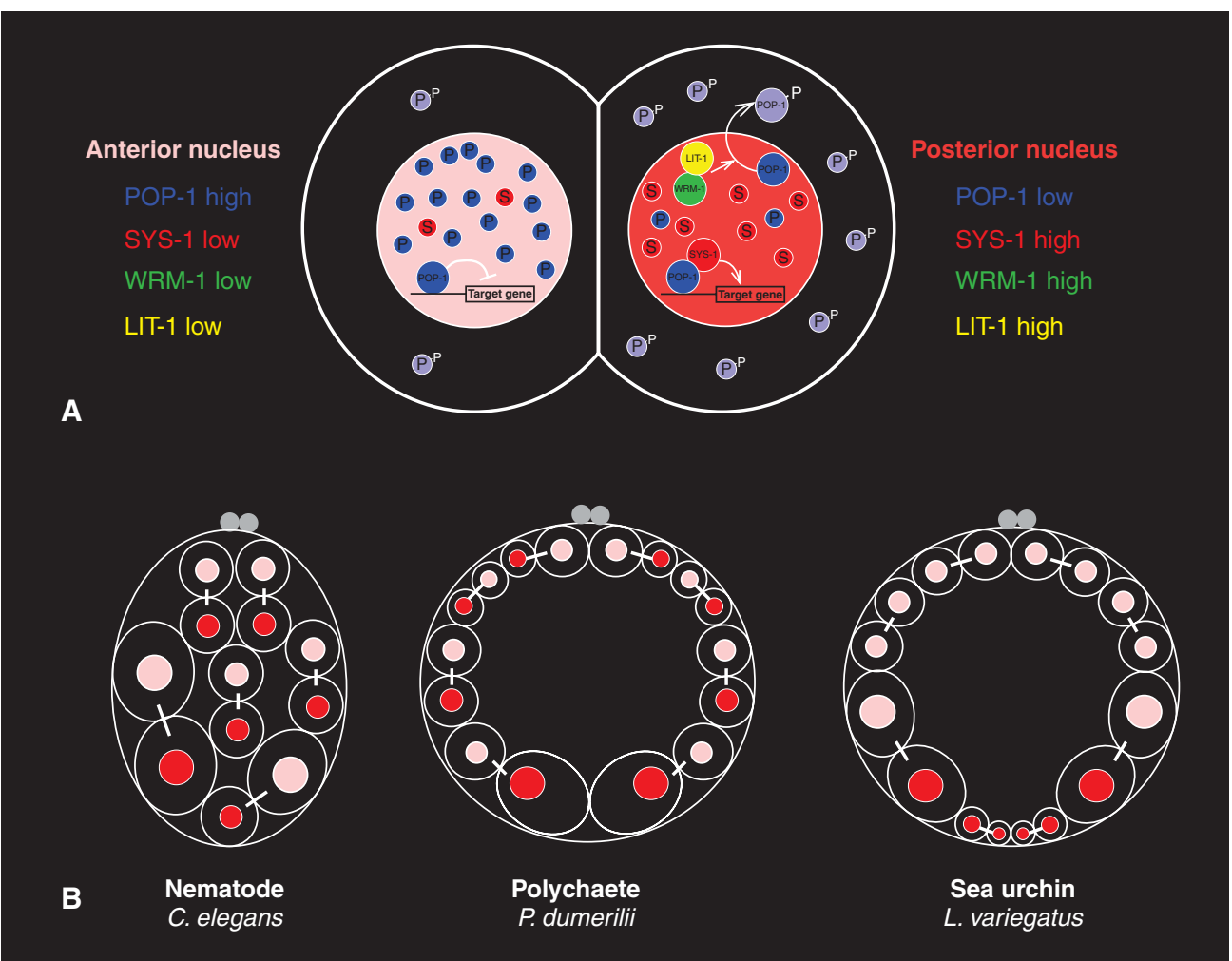

Figure 5. Binary specification and animal phylogeny. (A) Molecular asymmetries result in the C. elegans ortholog of TCF (POP-1) acting as a transcriptional repressor in anterior sister cells and as a transcriptional activator in posterior sisters. High levels of WRM- $1 / \beta$-catenin and LIT- $1 /$ NLK in posterior sisters promote the phosphorylation and export of most POP-1/TCF from posterior nuclei. High levels of SYS-1/ $\beta$-catenin in the posterior sisters then convert the remaining POP-1 molecules into transcriptional activators. In anterior sisters, most of the POP-1 molecules are not converted into activators by the lower levels of SYS-1 and repression results. $(B)$ Binary specification has been identified in two species, the nematode C. elegans and the polychaete annelid Platynereis dumerilii (both invertebrate protostomes). This similarity may be an example of evolutionary convergence, as $\beta$-catenin is restricted to vegetal pole nuclei in embryos of a sea urchin (an invertebrate deuterostome) and the nemertean (an invertebrate protostome).

early embryo, with an endoderm requirement for SYS-1 observed in only a small percentage of mutant embryos and a transcriptional activator called SKN-1 being largely responsible for specifying endoderm fate (Huang et al. 2007; Phillips et al. 2007). In contrast, SYS-1 conversion of POP-1 into a transcriptional activator is fully required for the specification of proximal sister-cell fate after asymmetric division of the somatic gonad precursor cells (Siegfried et al. 2004). Finally, recent studies of endoderm specification in the nematode Caenorhabiditis briggsae indicate that $C$. briggsae POP-1/TCF is required not as a repressor of mesoderm fate, as in C. elegans, but as an activator of endoderm fate (Lin et al. 2009). Thus the requirements for POP-1 as a transcriptional regulator are also subject to evolutionary variation.

In both C. elegans and Platynereis, $\beta$-catenin serves well as a regulator of binary specification, with ubiquitous expression, rapid proteolytic regulation, and an ability to convert TCF into a transcriptional activator. Apparently evolution has twice selected even very different $\beta$-catenins as universal reinforcers of sister-cell fate distinctions during the rapid development of relatively simple animal embryos with invariant cell lineages. 


\section{CONCLUDING REMARKS}

We have focused on two apparently distinct systems for breaking cellular symmetry during C. elegans development. In one, Par/Rho/ Cdc-42/Actomyosin establish and maintain AP polarity during the early asymmetric cell divisions that segregate posterior germline potential from anterior somatic cell fates, beginning with the first mitotic division of the one-cell zygote. A second symmetry-breaking system begins to operate at the four-cell stage, when a posterior blastomere produces a Wnt ligand that induces the asymmetric division of an adjacent ventral blastomere. As a result, this responding blastomere divides such that its posterior daughter produces endoderm whereas its anterior daughter produces mesoderm.

Both systems involve distinct sets of conserved molecular players and interactions; both are used reiteratively, with lineage specific modifications, to accomplish a sequence of related jobs. The Par/Rho/Cdc-42/Actomyosin network has been most extensively studied during the first mitotic division of the zygote, but it appears to be involved in all five of the asymmetric cell divisions that ultimately produce the single C. elegans germline precursor, whereas elements of this network operate during cleavage furrow specification and the establishment of apico-basal polarity. The Wnt pathway mediated symmetry-breaking system, here called binary specification, is remarkably reiterative, influencing many if not all sister cell fate distinctions that are made whenever an embryonic or larval cell divides along the AP axis, beginning when the ventral-most blastomere in a four-cell stage embryo divides along the AP axis. Again, the different variants of binary specification that have been characterized thus far appear to involve stage- and/or lineage-specific modifications of a fundamentally conserved pathway.

Two areas of future research promise to advance our understanding of the Par/Rho/ Cdc-42/Actomyosin symmetry-breaking system in the near term. First, understanding the mechanics of symmetry breaking in the onecell C. elegans zygote will require an expanded use of computational modeling. Critically, these modeling efforts must be coupled to quantitative measurements of force, molecular concentrations, fluxes, and binding affinities, as recently emphasized in studies of fission yeast cytokinesis (Wu and Pollard 2005; Vavylonis et al. 2008). Such information should greatly improve our ability to understand how symmetry breaking can be done by continuous remodeling of a dynamic contractile actomyosin cortex, as opposed to the other symmetrybreaking systems in which the entire cortical system collapses away from a single weakened point or region (see Vladar et al. 2009). Second, the further exploitation of genetic tools and specific gene alleles to bypass early requirements for the Par/Rho/Cdc-42/Actomyosin system should allow us to greatly improve our currently much more limited understanding of how variants of this network operate during apical/basal symmetry breaking in early embryonic cells and in later appearing epithelial tissues. It also will be interesting to learn to what extent the interplay between Par proteins, Rho GTPases, and actomyosin contractility mediate symmetry breaking in other organisms.

The Wnt-related binary specification system appears to be limited thus far to two animal phyla, and to two animal species (the nematode C. elegans and the annelid P. dumerilii) that develop rapidly with invariant embryonic cell lineages. Although molecular genetic studies of Wnt/ $\beta$-catenin-mediated binary specification in $C$. elegans will continue to improve our mechanistic understanding of this process, it will be particularly interesting to learn if other animals use such a reiterative symmetrybreaking system in more limited fashion compared with $C$. elegans and Platynereis. For example, it will be interesting to learn if such a system is used during stem-cell development or organogenesis in vertebrates and other animal phyla.

Clearly we have much yet to learn about the mechanisms that mediate symmetry breaking in single embryonic cells. As a master of this art, the C. elegans embryo should continue to provide new and exciting insights into this most fundamental of developmental processes for a long time to come. 


\section{ACKNOWLEDGMENTS}

The authors gratefully acknowledge support from the NIGMS. Ed Munro thanks the Friday Harbor Labs and staff for providing a supportive working environment. The authors also are grateful to Stephan Schneider for making Figure 5.

\section{REFERENCES}

Aceto D, Beers M, Kemphues KJ. 2006. Interaction of PAR-6 with CDC-42 is required for maintenance but not establishment of PAR asymmetry in C. elegans. Dev Biol 299: 386-397.

Anderson DC, Gill JS, Cinalli RM, Nance J. 2008. Polarization of the C. elegans embryo by RhoGAPmediated exclusion of PAR-6 from cell contacts. Science 320: $1771-1774$.

Aono S, Legouis R, Hoose WA, Kemphues KJ. 2004. PAR-3 is required for epithelial cell polarity in the distal spermatheca of C. elegans. Development 131: 2865-2874.

Asahina M, Valenta T, Silhankova M, Korinek V, Jindra M. 2006. Crosstalk between a nuclear receptor and $\beta$-catenin signaling decides cell fates in the $C$. elegans somatic gonad. Dev Cell 11: 203-211.

Baruni JK, Munro EM, von Dassow G. 2008. Cytokinetic furrowing in toroidal, binucleate and anucleate cells in C. elegans embryos. J Cell Sci 121: 306-316.

Beers M, Kemphues K. 2006. Depletion of the co-chaperone CDC-37 reveals two modes of PAR-6 cortical association in C. elegans embryos. Development 133: 3745-3754.

Benton R, St Johnston D. 2003. Drosophila PAR-1 and 143-3 inhibit Bazooka/PAR-3 to establish complementary cortical domains in polarized cells. Cell 115: 691-704.

Bertrand V, Hobert O. 2009. Linking asymmetric cell division to the terminal differentiation program of postmitotic neurons in C. elegans. Dev Cell 16: 563-575.

Bischoff M, Schnabel R. 2006. A posterior centre establishes and maintains polarity of the Caenorhabditis elegans embryo by a Wnt-dependent relay mechanism. PLoS Biol 4: e396.

Bringmann H, Hyman AA. 2005. A cytokinesis furrow is positioned by two consecutive signals. Nature 436: 731-734.

Boyd L, Guo S, Levitan D, Stinchcomb DT, Kemphues KJ. 1996. PAR-2 is asymmetrically distributed and promotes association of $\mathrm{P}$ granules and PAR-1 with the cortex in C. elegans embryos. Development 122: 3075-3084.

Bringmann H, Cowan CR, Kong J, Hyman AA. 2007. LET-99, GOA-1/GPA-16, and GPR-1/2 are required for aster-positioned cytokinesis. Curr Biol 17: 185-191.

Cowan CR, Hyman AA. 2004a. Asymmetric cell division in C. elegans: Cortical polarity and spindle positioning. Annu Rev Cell Dev Biol 20: 427-453.

Cowan CR, Hyman AA. 2004b. Centrosomes direct cell polarity independently of microtubule assembly in C. elegans embryos. Nature 431: 92-96.
Cowan CR, Hyman AA. 2006. Cyclin E-Cdk2 temporally regulates centrosome assembly and establishment of polarity in Caenorhabditis elegans embryos. Nat Cell Biol 8: 1441-1447.

Cuenca AA, Schetter A, Aceto D, Kemphues K, Seydoux G. 2003. Polarization of the C. elegans zygote proceeds via distinct establishment and maintenance phases. Development 130: 1255-1265.

Dechant R, Glotzer M. 2003. Centrosome separation and central spindle assembly act in redundant pathways that regulate microtubule density and trigger cleavage furrow formation. Dev Cell 4: 333-344.

Etemad-Moghadam SG, Kemphues KJ. 1995. Asymmetrically distributed PAR-3 protein contributes to cell polarity and spindle alignment in early C. elegans embryos. Cell 83: 743-752.

Foe VE, von Dassow G. 2008. Stable and dynamic microtubules coordinately shape the myosin activation zone during cytokinetic furrow formation. J Cell Biol 183: 457-470.

Galli M, Van den Heuvel S. 2008. Determination of the cleavage plane in early C. elegans embryos. Annu Rev Genet 42: $389-411$.

Goldstein B, Hird SN. 1996. Specification of the anteroposterior axis in Caenorhabditis elegans. Development 122: 1467-1474.

Goldstein B, Macara IG. 2007. The PAR proteins: Fundamental players in animal cell polarization. Dev Cell 13: 609-622.

Goldstein B, Takeshita H, Mizumoto K, Sawa H. 2006. Wnt signals can function as positional cues in establishing cell polarity. Dev Cell 10:391-396.

Gotta M, Abraham MC, Ahringer J. 2001. CDC-42 controls early cell polarity and spindle orientation in C. elegans. Curr Biol 11: 482-488.

Green JL, Inoue T, Sternberg PW. 2008. Opposing Wnt pathways orient cell polarity during organogenesis. Cell 134: 646-656.

Guo S, Kemphues KJ. 1995. Par-1, a gene required for establishing polarity in C. elegans embryos, encodes a putative ser/thr kinase that is asymmetrically distributed. Cell 81: 611-620.

Hamill DR, Severson AF, Carter JC, Bowerman B. 2002. Centrosome maturation and mitotic spindle assembly in C. elegans require SPD-5, a protein with multiple coiled-coil domains. Dev Cell 3: 673-684.

Hao Y, Boyd L, Seydoux G. 2006. Stabilization of cell polarity by the C. elegans RING protein PAR-2. Dev Cell 10: 199-208.

Hawkins NC, Ellis GC, Bowerman B, Garriga G. 2005. MOM-5 frizzled regulates the distribution of DSH-2 to control C. elegans asymmetric neuroblast divisions. Dev Biol 284: 246-259.

Henry JQ, Perry KJ, Wever J, Seaver E, Martindale MQ. 2008. $\beta$-catenin is required for the establishment of vegetal embryonic fates in the nemertean, Cerebratulus lacteus. Dev Biol 317: 368-379.

Hird SN, White JG. 1993. Cortical and cytoplasmic flow polarity in early embryonic cells of Caenorhabditis elegans. J Cell Biol 121: 1343-1355. 
E. Munro and B. Bowerman

Huang S, Shetty P, Robertson SM, Lin R. 2007. Binary cell fate specification during C. elegans embryogenesis driven by reiterated reciprocal asymmetry of TCF POP-1 and its coactivator $\beta$-catenin SYS-1. Development 134: 2685-2695.

Hubbard EJ, Greenstein D. 2000. The Caenorhabditis elegans gonad: A test tube for cell and developmental biology. Dev Dyn 218: 2-22.

Hung TJ, Kemphues KJ. 1999. PAR-6 is a conserved PDZ domain-containing protein that colocalizes with PAR-3 in Caenorhabditis elegans embryos. Development 126: 127-135.

Jenkins N, Saam JR, Mango SE. 2006. CYK-4/GAP provides a localized cue to initiate anteroposterior polarity upon fertilization. Science 313: 1298-1301.

Kaletta T, Schnabel H, Schnabel R. 1997. Binary specification of the embryonic lineage in Caenorhabditis elegans. Nature 390: 294-298.

Kemphues KJ, Priess JR, Morton DG, Cheng NS. 1988. Identification of genes required for cytoplasmic localization in early C. elegans embryos. Cell 52: 311-320.

Kidd AR 3rd, Miskowski JA, Siegfried KR, Sawa H, Kimble J. 2005. A $\beta$-catenin identified by functional rather than sequence criteria and its role in Wnt/MAPK signaling. Cell 121: 761-772.

King RS, Maiden SL, Hawkins NC, Kidd AR 3rd, Kimble J, Hardin J, Walston TD. 2009. The N- or C-terminal domains of DSH-2 can activate the C. elegans Wnt/ $\beta$-catenin asymmetry pathway. Dev Biol 328: 234-244.

Kirby C, Kusch M, Kemphues KJ. 1990. Mutations in the par genes of $C$. elegans affect cytoplasmic reorganization during the first cell cycle. Dev Biol 142: 203-215.

Labouesse M. Epithelial junctions and attachments. 2006. WormBook, ed. The C. elegans Research Community, WormBook, doi/10.1895/wormbook.1.56, http://www.wormbook.org.

Lam N, Chesney MA, Kimble J. 2006. Wnt signaling and CEH-22/tinman/Nkx2.5 specify a stem cell niche in C. elegans. Curr Biol 16: 287-295.

Larabell CA, Torres M, Rowning BA, Yost C, Miller JR, Wu M, Kimelman D, Moon RT. 1997. Establishment of the dorso-ventral axis in Xenopus embryos is presaged by early asymmetries in $\beta$-catenin that are modulated by the Wnt signaling pathway. J Cell Biol 136: 1123-1136.

Li H, Guo F, Rubinstein B, Li R. 2008. Actin-driven chromosomal motility leads to symmetry breaking in mammalian meiotic oocytes. Nat Cell Biol 10: 1301-1308.

Lin R, Thompson S, Priess JR. 1995. pop-1 encodes an HMG box protein required for the specification of a mesoderm precursor in early C. elegans embryos. Cell 83: 599-609.

Lin R, Hill R, Priess JR. 1998. POP-1 and anterior-posterior fate decision in C. elegans embryos. Cell 92: 229-240.

Lin KT, Broitman Maduro G, Hung WW, Cervantes S, Maduro MF. 2009. Knockdown of SKN-1 and the Wnt effector TCF/POP-1 reveals differences in endomesoderm specification in C. briggsae as compared with C. elegans. Dev Biol 325: 296-306.

Logan CY, Miller JR, Ferkowicz MJ, McClay DR. 1999. Nuclear $\beta$-catenin is required to specify vegetal cell fates in the sea urchin embryo. Development 126: $345-357$.
Meneghini MD, Ishitani T, Carter JC, Hisamoto N, Ninomiya-Tsuji J, Thorpe CJ, Hamill DR, Matsumoto K, Bowerman B. 1999. MAP kinase and Wnt pathways converge to downregulate an HMG-domain repressor in Caenorhabditis elegans. Nature 399: 793-798.

Mizumoto K, Sawa H. 2007. Two betas or not two betas: Regulation of asymmetric division by $\beta$-catenin. Trends Cell Biol 17: 465-473.

Motegi F, Sugimoto A. 2006. Sequential functioning of the ECT-2 RhoGEF, RHO-1 and CDC-42 establishes cell polarity in Caenorhabditis elegans embryos. Nat Cell Biol 8: 978-985.

Motegi F, Velarde NV, Piano F, Sugimoto A. 2006. Two phases of astral microtubule activity during cytokinesis in C. elegans embryos. Dev Cell 10: 509-520.

Mullins D. 2009. Cytoskeletal mechanisms for breaking cellular symmetry. Cold Spring Harb Perspect Biol 2: a003392.

Munro EM. 2006. PAR proteins and the cytoskeleton: A marriage of equals. Curr Opin Cell Biol 18: 86-94.

Munro E, Nance J, Priess JR. 2004. Cortical flows powered by asymmetrical contraction transport PAR proteins to establish and maintain anterior-posterior polarity in the early C. elegans embryo. Dev Cell 7: 413-424.

Murthy K, Wadsworth P. 2008. Dual role for microtubules in regulating cortical contractility during cytokinesis. J Cell Sci 121: 2350-2359.

Nakamura K, Kim S, Ishidate T, Bei Y, Pang K, Shirayama M, Trzepacz C, Brownell DR, Mello CC. 2005. Wnt signaling drives WRM- $1 / \beta$-catenin asymmetries in early $C$. elegans embryos. Genes Dev 19: 1749-1754.

Nance J, Priess JR. 2002. Cell polarity and gastrulation in C. elegans. Development 129: 387-397.

Nance J, Munro EM, Priess JR. 2003. C. elegans PAR-3 and PAR-6 are required for apicobasal asymmetries associated with cell adhesion and gastrulation. Development 130: 5339-5350.

Nishimura Y, Yonemura S. 2006. Centralspindlin regulates ECT2 and RhoA accumulation at the equatorial cortex during cytokinesis. J Cell Sci 119: 104-114.

Nusse R. 2005. Wnt signaling in disease and in development. Cell Res 15: 28-32.

O'Connell KF, Maxwell KN, White JG. 2000. The spd-2 gene is required for polarization of the anteroposterior axis and formation of the sperm asters in the Caenorhabditis elegans zygote. Dev Biol 222: 55-70.

Paluch E, Piel M, Prost J, Bornens M, Sykes C. 2005. Cortical actomyosin breakage triggers shape oscillations in cells and cell fragments. Biophys $J$ 89: 724-733.

Park FD, Priess JR. 2003. Establishment of POP-1 asymmetry in early C. elegans embryos. Development 130: 3547-56.

Park FD, Tenlen JR, Priess JR. 2004. C. elegans MOM-5/ frizzled functions in MOM-2/Wnt-independent cell polarity and is localized asymmetrically prior to cell division. Curr Biol 14: 2252-2258.

Phillips BT, Kidd AR 3rd, King R, Hardin J, Kimble J. 2007. Reciprocal asymmetry of SYS- $1 / \beta$-catenin and POP- 1 / TCF controls asymmetric divisions in Caenorhabditis elegans. Proc Natl Acad Sci 104: 3231-3236. 
Pilipiuk J, Lefebvre C, Wiesenfahrt T, Legouis R, Bossinger O. 2009. Increased IP3/Ca2 + signaling compensates depletion of LET-413/DLG-1 in C. elegans epithelial junction assembly. Dev Biol 327: 34-47.

Portereiko MF, Saam J, Mango SE. 2004. ZEN-4/MKLP1 is required to polarize the foregut epithelium. Curr Biol 14: 932-941.

Priess JR, Hirsh DI. 1986. Caenorhabditis elegans morphogenesis: The role of the cytoskeleton in elongation of the embryo. Dev Biol 117: 155-173.

Rocheleau CE, Yasuda J, Shin TH, Lin R, Sawa H, Okano H, Priess JR, Davis RJ, Mello CC. 1999. WRM-1 activates the LIT-1 protein kinase to transduce anterior/posterior polarity signals in C. elegans. Cell 94: 717-726.

Schlesinger A, Shelton CA, Maloof JN, Meneghini M, Bowerman B. 1999. Wnt pathway components orient a mitotic spindle in the early $C$. elegans embryo without requiring gene transcription in the responding cell. Genes Dev 13: 2028-2038.

Schmutz C, Stevens J, Spang A. 2007. Functions of the novel RhoGAP proteins RGA-3 and RGA-4 in the germ line and in the early embryo of C. elegans. Development 134: 3495-3505.

Schneider SQ, Bowerman B. 2003. Cell polarity and the cytoskeleton in the Caenorhabditis elegans zygote. Annu Rev Genet 37: 221-249.

Schneider SQ, Bowerman B. 2007. $\beta$-Catenin asymmetries after all animal/vegetal-oriented cell divisions in Platynereis dumerilii embryos mediate binary cell-fate specification. Dev Cell 13: 73-86.

Schneider S, Steinbeisser H, Warga RM, Hausen P. 1996. $\beta$-catenin translocation into nuclei demarcates the dorsalizing centers in frog and fish embryos. Mech Dev 57: 191-198.

Schneider SQ, Finnerty JR, Martindale MQ. 2003 Protein evolution: Structure-function relationships of the oncogene $\beta$-catenin in the evolution of multicellular animals. J Exp Zoolog B Mol Dev Evol 295: $25-44$.

Schonegg S, Hyman AA. 2006. CDC-42 and RHO-1 coordinate acto-myosin contractility and PAR protein localization during polarity establishment in C. elegans embryos. Development 133: 3507-3516.

Schonegg S, Constantinescu AT, Hoege C, Hyman AA. 2007. The Rho GTPase-activating proteins RGA-3 and RGA-4 are required to set the initial size of PAR domains in Caenorhabditis elegans one-cell embryos. Proc Natl Acad Sci 104: 14976-14981.

Shelton CA, Carter JC, Ellis GC, Bowerman B. 1999. The nonmuscle myosin regulatory light chain gene mlc- 4 is required for cytokinesis, anterior-posterior polarity, and body morphology during Caenorhabditis elegans embryogenesis. J Cell Biol 146: 439-451.

Siegfried KR, Kidd AR 3rd, Chesney MA, Kimble J. 2004. The sys- 1 and sys-3 genes cooperate with Wnt signaling to establish the proximal-distal axis of the Caenorhabditis elegans gonad. Genetics 166: 171-186.

Somers WG, Saint R. 2003. A RhoGEF and Rho family GTPase-activating protein complex links the contractile ring to cortical microtubules at the onset of cytokinesis. Dev Cell 4: 29-39.
Sonneville R, Gonczy P. 2004. Zyg-11 and cul-2 regulate progression through meiosis II and polarity establishment in C. elegans. Development 131: 3527-3543.

Strome S, Wood WB. 1983. Generation of asymmetry and segregation of germ-line granules in early C. elegans embryos. Cell 35: 15-25.

Sulston JE, Horvitz HR. 1977. Post-embryonic cell lineages of the nematode, Caenorhabditis elegans. Dev Biol 56: $110-156$.

Sulston JE, Schierenberg E, White JG, Thomson JN. 1983. The embryonic cell lineage of the nematode Caenorhabditis elegans. Developmental Biology 100: 64-119.

Tabuse Y, Izumi Y, Piano F, Kemphues KJ, Miwa J, Ohno S. 1998. Atypical protein kinase C cooperates with PAR-3 to establish embryonic polarity in Caenorhabditis elegans. Development 125: 3607-3614.

Takeshita H, Sawa H. 2005. Asymmetric cortical and nuclear localizations of WRM- $1 / \beta$-catenin during asymmetric cell division in C. elegans. Genes Dev 19: 1743-1748.

Taunton J, Rowning BA, Coughlin ML, Wu M, Moon RT, Mitchison TJ, Larabell CA. 2000. Actin-dependent propulsion of endosomes and lysosomes by recruitment of N-WASP. J Cell Biol 148: 519-530.

Theriot JA, Mitchison TJ. 1992. Comparison of actin and cell surface dynamics in motile fibroblasts. J Cell Biol 119: 367-377.

Thorpe CJ, Moon RT. 2004. nemo-like kinase is an essential co-activator of Wnt signaling during early zebrafish development. Development 131: 2899-2909.

Thorpe CJ, Schlesinger A, Bowerman B. 2000. Wnt signalling in Caenorhabditis elegans: Regulating repressors and polarizing the cytoskeleton. Trends Cell Biol 10: $10-17$.

Totong R, Achilleos A, Nance J. 2007. PAR-6 is required for junction formation but not apicobasal polarization in C. elegans embryonic epithelial cells. Development 134: $1259-1268$.

Tsai MC, Ahringer J. 2007. Microtubules are involved in anterior-posterior axis formation in C. elegans embryos. J Cell Biol 179: 397-402.

van der Gucht J, Sykes C. 2009. Physical model of cellular symmetry breaking. Cold Spring Harb Perspect Biol 1: a001909.

Vavylonis D, Wu JQ, Hao S, O'Shaughnessy B, Pollard TD. 2008. Assembly mechanism of the contractile ring for cytokinesis by fission yeast. Science 319: 97-100.

Velarde N, Gunsalus KC, Piano F. 2007. Diverse roles of actin in C. elegans early embryogenesis. BMC Dev Biol 7: 142 .

Wallenfang MR, Seydoux G. 2000. Polarization of the anterior-posterior axis of C. elegans is a microtubuledirected process. Nature 408: 89-92.

Watanabe N, Mitchison TJ. 2002. Single-molecule speckle analysis of actin filament turnover in lamellipodia. Science 295: 1083-1086.

Werner M, Munro E, Glotzer M. 2007. Astral signals spatially bias cortical myosin recruitment to break symmetry and promote cytokinesis. Curr Biol 17: 1286-1297. 


\section{E. Munro and B. Bowerman}

White JG, Borisy GG. 1983. On the mechanisms of cytokinesis in animal cells. J Theor Biol 101: 289-316.

Wu M, Herman MA. 2006. A novel noncanonical Wnt pathway is involved in the regulation of the asymmetric B cell division in C. elegans. Dev Biol 293: 316-329.

Wu M, Herman MA. 2007. Asymmetric localizations of LIN-17/Fz and MIG-5/Dsh are involved in the asymmetric B cell division in C. elegans. Dev Biol 303: 650-662.

Wu JQ, Pollard TD. 2005. Counting cytokinesis proteins globally and locally in fission yeast. Science 310: 310-314.

Yuce O, Piekny A, Glotzer M. 2005. An ECT2-centralspindlin complex regulates the localization and function of RhoA. J Cell Biol 170: 571-582. 


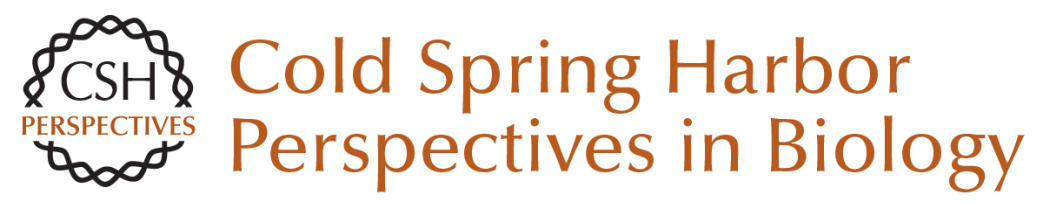

\section{Cellular Symmetry Breaking during Caenorhabditis elegans Development}

\section{Edwin Munro and Bruce Bowerman}

Cold Spring Harb Perspect Biol 2009; doi: 10.1101/cshperspect.a003400 originally published online September 16, 2009

\section{Subject Collection Symmetry Breaking in Biology}

Cytoskeletal Mechanisms for Breaking Cellular Symmetry

R. Dyche Mullins

Symmetry Breaking in Biology

Rong Li and Bruce Bowerman

Planar Cell Polarity Signaling: The Developing Cell's Compass

Eszter K. Vladar, Dragana Antic and Jeffrey D. Axelrod

Cellular Polarity in Prokaryotic Organisms Jonathan Dworkin

Symmetry Breaking in Plants: Molecular Mechanisms Regulating Asymmetric Cell Divisions in Arabidopsis

Jalean J. Petricka, Jaimie M. Van Norman and Philip N. Benfey

The Signaling Mechanisms Underlying Cell Polarity and Chemotaxis Fei Wang

Polarization of Drosophila Neuroblasts During

Asymmetric Division Kenneth E. Prehoda
Polarity in Stem Cell Division: Asymmetric Stem Cell Division in Tissue Homeostasis

Yukiko M. Yamashita, Hebao Yuan, Jun Cheng, et al.

Symmetry Breaking in the Life Cycle of the

Budding Yeast

Brian D. Slaughter, Sarah E. Smith and Rong Li

Neuronal Polarity

Sabina Tahirovic and Frank Bradke

\author{
Membrane Organization and Dynamics in Cell \\ Polarity \\ Kelly Orlando and Wei Guo \\ Cellular Symmetry Breaking during \\ Caenorhabditis elegans Development \\ Edwin Munro and Bruce Bowerman
}

Symmetry Breaking During Drosophila Oogenesis Siegfried Roth and Jeremy A. Lynch

Widely Conserved Signaling Pathways in the

Establishment of Cell Polarity

Luke Martin McCaffrey and lan G. Macara

For additional articles in this collection, see http://cshperspectives.cshlp.org/cgi/collection/

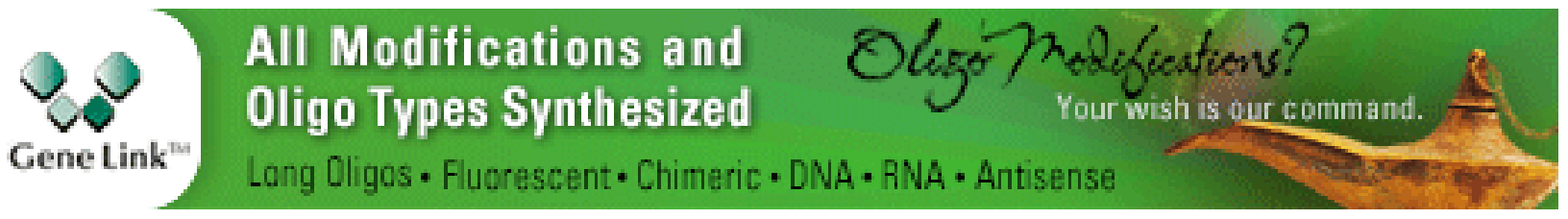

Copyright @ 2009 Cold Spring Harbor Laboratory Press; all rights reserved 

Physical Model of Cellular Symmetry Breaking
Jasper van der Gucht and Cécile Sykes
Shaping Fission Yeast with Microtubules Fred Chang and Sophie G. Martin

For additional articles in this collection, see http://cshperspectives.cshlp.org/cgi/collection/

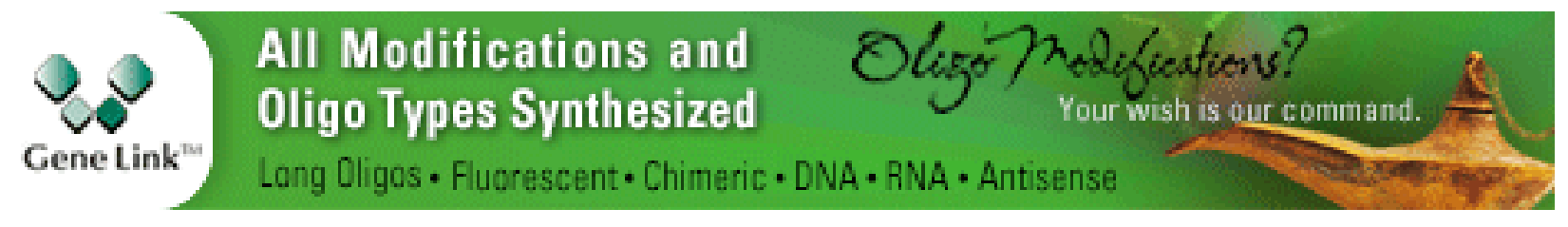

Copyright @ 2009 Cold Spring Harbor Laboratory Press; all rights reserved 